\title{
SLOWENISCH ALS FREMDSPRACHE
}

0 Nicht ganz zwei Millionen Menschen sprechen Slowenisch als Muttersprache. Wenige gibt es, die das Slowenische zwar sprechen oder zu sprechen versuchen, aber eine andere Muttersprache haben, vielleicht hunderttausend; für die ist slowenisch also eine Fremdsprache.

Das Slowenische ist bekanntlich eine slawische sprache, die westlichste von den südslawischen Sprachen, eingekeilt zwischen das Italienische bzw. das Friaulische im Westen, das Deutsche im Norden, das Ungarische im Nordosten, eng verwandt mit dem Serbokroatischen im Osten und nicht ohne ältere und jüngere Verbindungen (letztere hauptsächlich aus der zweiten Hälfte des 19. Jahrhunderts) mit den westslawischen Sprachen, vornehmlich mit dem Tschechischen und Slowakischen, auch im genetischen Sinne; darüber hinaus gibt es auch Lehnbeziehungen zum Russischen. slowenisch wird heute hauptsächlich in der Sozialistischen Republik Slowenien in Jugoslawien gesprochen, es gibt jedoch auch ausserhalb Jugoslawiens auf dem slowenischen Nationalterritorium Slowenen und zwar in Ungarn (die Raab-Slowenen), in österreich (die Kärntner Slowenen) und in Italien (Kärntner Slowenen in der Gegend von Tarvisio, die Resianer in Resiatal, die Venetianer slowenen im Gebiet von Ter und Natisone, ferner die slowenen nördlich und im Umkreis der stadt Gorizia, und von dort nach süden ununterbrochen über den Karst hinweg bis Triest und weiter bis zur italienisch-jugoslawischen staatsgrenze. In allen Gebieten ausserhalb sloweniens leben die Slowenen zum Teil stark vermischt mit der jeweiligen Nachbarbevölkerung, d.h. mit den Ungarn, 
Österreichern, Italienern und Friaulern, sie leben jedoch noch immer hauptsächlich auf geschlossenem Gebiet, zum Teil in einem Majoritätsverhältnis, hauptsächlich jedoch in einem Minoritätsverhältnis gegenüber der anderssprachigen Bevölkerung. An gewissen Stellen, besonders in städten, wie z.B. Klagenfurt, Gorizia, Triest, sind die slowenen bereits vollkommen zersplittert, verstreut sozusagen unter die anderssprachige Bevölkerung. Sie leben also nicht mehr in geschlossenen Wohngebieten, zum Beispiel Stadtteilen oder Strassen und werden zum Teil nur durch Unterrichts- und andere Kultur- und Kultusanstalten und -veranstaltungen integriert, zum Beispiel auch durch die slowenischsprachige Publizistik.

Solche dispersen Slowenen gibt es dann auch zum Teil schon im nichtslowenischen Teil von Jugoslawien lobwohl sie auf diesen Gebieten, sobald sie fest ansässig werden, schnell in der anderssprachigen Lebensgemeinschaft aufgehen), ferner bei den emigrierten Slowenen in Europa (Bundesrepublik Deutschland, Schweden, Schweiz, Niederlande, Belgien, Frankreich - Italien wohl kaum), in Nordamerika (Vereinigte Staaten und Kanada), in Sudamerika (Argentinien) und schliesslich in Australien.

1 Eine Sprache, die wenige Leute sprechen, wird von Anderssprachigen gewöhnlich nicht gelernt, vielmehr ist es üblich, dass die Träger einer solchen sprache selbst andere Sprachen lernen, damit es zu sprachkommunikationsbeziehungen zwischen ihnen und den Anderssprachigen kommt. In diesem Sinne bilden vor allem auch die Mischehen ausserhalb Sloweniens in Jugoslawien keine Ausnahme.

Das kann also nur im jugoslawischen slowenien anders sein. Da wirkt das slowenische als eine - wie ich das nenne - Ma-Sprache $($ Ma $=$ maior), und andere sprachen geraten da in eine Mi-stellung $(M i=$ minor), wodurch das Slowenische als eine Fremdsprache zur Existenz gelangt. Wir müssen uns also die Verhältnisse näher betrachten, denen wir in dieser Hinsicht in Slowenien begegnen.

1.1. Wenn wir die Roma (zigeuner) ausnehmen, weil sie ein spezielles Problem darstellen, dann gibt es in Slowenien zwei Gegenden, in denen anderssprachige autochtone sprachgemeinschaf- 
ten leben: in der Umgebung von Koper (und in Koper selbst) leben neben den Slowenen auch Italiener, im Gebiet von Lendava sind auch Ungarn ansässig.

Weil in der Republik Slowenien als dem Nationalstaat der Slowenen in der föderativen Republik Jugoslawien Slowenisch die meist gebrauchte Sprache ist, wäre es - wenn schon nicht verbindlich, so doch vernünftig - wenn für die nichtslowenische Bevölkerung in Slowenien das Slowenische eine sprache wäre, die gelernt werden müsste. Und zwar schon deshalb, damit sich ein Sprachkontakt zur Majoritätsbevölkerung aufnehmen lässt, aber auch, damit auf den höheren Schulen (angefangen bei den Mittelschulen verschiedenster Richtungen bis hinauf $\mathrm{zu}$ Hochschulen und Universitäten) an der Ausbildung teilgenommen werden kann, und endlich um der Möglichkeit willen, auch ausserhalb der naturgemäss enggehaltenen Grenzen der Beschäftigungsmöglichkeiten im eigenen (noch dazu meist gemischten) Sprachgebiet eine Arbeit zu finden und auszuüben.

1. 2 Ungefähr so sollte es eben mit jenen Nichtslowenen sein, die in unserer slowenischen Mitte zerstreut leben. Das sind schon seit der Gründung des jugoslawischen staates nach dem ersten Weltkrieg zunächst die Angehörigen der Armee, in der laut Verfassung und in Praxis Serbokroatisch als Unterrichts-, Verwaltungs- und Kommandosprache gilt. Dann haben wir eine dünne Schicht von Verwaltungsbeamten bei den Grenzbehörden, besonders bei der zollbehörde (dabei handelt es sich nicht nur um die zollämter unmittelbar an den Grenzübergängen, sondern auch in den grösseren (Ljubljana, Maribor) oder kleineren für den zoll wichtigeren Städten (Sežana, Jesenice, Nova Gorica, Koper)), und schliesslich gibt es da noch Leute (mit über 100000 zahlenmässig die stärkste Gruppe), die in slowenien leben, weil sie dort im zivilen Leben eine Arbeit gefunden haben. Denen misste man noch die an slowenischen Lehranstalten sich ausbildenden Mittelschüler und studenten hinzurechnen.

1. 3 Für den Zweck der uns hier interessierenden Frage ist es wichtig zu wissen, welche Sprachen von diesen Immigranten gesprochen werden. 
Die meisten dieser Immigrierten haben Serbokroatisch als Muttersprache, und zwar in den verschiedenen Dialektalabzweigungen, hauptsächlich jedoch in der kajkavischen, die dem slowenischen sehr nahe sind (das sind die Kroaten) und der stokavischen (das können zwar auch Kroaten sein, hauptsächlich sind es jedoch Bosnier, einschliesslich der Herzegowiner, und Serben der verschiedenen jugoslawischen Volksrepubliken (diese scheinen auch unter den Militärs stärker vertreten zu sein). Die zweite Stelle unter den Immigrierten nehmen dann die Albaner aus Kosovo ein, an dritter stehen die studenten aus verschiedenen Ländern, hauptsächlich aus der dritten Welt; auch die Makedonier fehlen nicht; und schliesslich verschiedene Experten aus den westlichen Ländern (seltener aus dem Osten), die zeitweilig unter uns leben. zuletzt wären noch die Turisten zu erwähnen.

2. Für alle diese Leute stellt die slowenische sprache die potenzielle Lernsprache dar. Inwieweit sie das auch wirklich wira, davon soll nun im weiteren die Rede sein.

2.1 Die Nichtslowenischsprachigen mit einem festen, ererbten Sprachterritorium in Slowenien sind laut unserem Verfassungsrecht zunächst, d.h. in der Volksschule, nicht gleich verpflichtet Slowenisch $z u$ lernen. Grundsätzlich besuchen sie ihre eigenen Volksschulen, und es ist verschieden, wie sie slowenisch als Pflichtfach lernen; das gilt auch für jene schüler der serbokroatischen Sprachgemeinschaft, deren Eltern längere zeit (und die Schüler oft überhaupt) in Slowenien leben (hauptsächlich die Militärs), ihre kinder aber zur serbokroatischen schule schicken (von solchen Schulen existiert in slowenien eine in Ljubljana), es können aber auch serbokroatisch sprechende kinder mit Bussen zu einer schule mit serbokroatischer Unterrichtssprache ausserhalb sloweniens gefahren werden, z.B. aus Brežice in slowenien nach Bregana in Kroatien. Für die Volksschulen mit serbokroatischer Unterrichtssprache in Slowenien besteht keine Verpflichtung auch Slowenisch als Pflichtfach zu führen; umgekehrt ist das Serbokroatische Pflichtfach in Volksschulen mit slowenischer Unterrichtssprache.

Im Gebiet um Gornja Lendava ist die Sache insofern anders, 
als es da seit ungefähr zehn Jahren nur solche Volksschulen gibt; in denen beide Sprachen, d.h. Slowenisch und Ungarisch, zugleich Unterrichtssprachen sind, wodurch also slowenisch für ungarisch sprechende Schüler Fremdsprache ist (und umgekehrt), die eigentlich ziemlich gut gelernt werden müsste und angeblich auch wird. So ist es im Westen mit dem Italienischen und Slowenischen nicht, obwohl da Slowenisch wohl eine potentielle Fremasprache für die italienisch sprechenden schüler ist.

2.2 Einen solchen, eigentlich nur potentiellen Fremdsprachenstatus, hat das slowenische auch in Ungarn, österreich und Italien auf jenen Gebieten, von denen einführend die Rede war. Das heisst: die ungarisch, deutsch und italienisch loder friaulisch) sprechenden Kinder lernen in der Praxis kein slowenisch, wohl aber wieder umgekehrt die slowenisch sprechenden Kinder die jeweilige andere Sprache, a.h. Ungarisch, Deutsch oder Italienisch (Friaulisch wohl kaum); unmittelbar nach dem zweiten weltkrieg war das in kärnten anders. Genauso ist es mit dem slowenischen bei unseren (zeitweiligen oder ständigen) Emigranten.

3 Das Slowenische ist aus dieser sicht eine Sprache mit einem nichtbevorzugten gesellschaftlichen status. Wäre das anders, dann gäbe es:

(1) Slowenisch als wichtiges Pflichtlehrfach in den Volks-. schulen, die Serbokroatisch oder Italienisch als Unterrichtssprachen führen;

(2) Slowenisch wenigstens als Unterrichtsfach (wenn nicht sogar als Mitunterrichtssprache) beim Militär in slowenien (oder in slowenischen Einheiten, falls solche auf nichtslowenischem Boden existieren oder existieren sollten);

(3) Slowenisch als Amtssprache bei allen Veranstaltungen, kulturellen und politischen, in slowenien, an denen auch slowenen teilnehmen, oder wenigstens solchen, die von slowenen organisiert werden und keinen internationalen charakter tragen, oder wenigstens solchen, an denen überwiegend slowenen teilnehmen;

(4) Slowenisch als gleichberechtige Sprache im Sprachverkehr mit Anderssprachigen, sei es, dass dieser auf slowenischem Boden stattfindet (in diesem Falle noch besonders) oder dass er 
einseitig von slowenischem Boden (und den betreffenden Institutionen und Anstalten) ausgeführt wird;

(5) das slowenische Experiment mit Mitunterrichtssprachen in der Volksschule würde zuerst im übrigen Jugoslawien selbst nachgeahmt werden, ausserhalb aber wenigstens noch in Ungarn, wenn nicht auch in österreich und Italien.

4 Jetzt müsste man wohl eine Teilung der Fremasprachen vornehmen. Die würde offensichtlich dahin auslaufen, dass es Fremdsprachen gibt, die für die Anderssprachigen wichtig loder wichtiger) sind, und solche, die sich dadurch eben nicht auszeichnen. Slowenisch gehört zu den letzteren. Slowenisch ist eine Sprache, die als Fremdsprache verhältnismässig wenig gelernt wird, auch in slowenien selbst.

5 Von wem aber wird slowenisch dennoch gelernt, in welchem Umfang und auf welchem Weg:

5.1 Beantworten wir zuerst die letzte Frage. - Slowenisch wird gewöhnlich durch die sprechpraxis gelernt, viel weniger durch den Sprach- und Sprechunterricht, und der umfang der Beherrschung dieser Sprache ist (natürlich) sehr verschieden. Die Sprechpraxis wird meist an den Arbeitsstellen geübt, wo Anderssprachige sich in einer vorwiegend oder ausschliesslich slowenischen Umgebung verständigen müssen. Solche voraussetzungen bestehen allerdings nicht häufig, und auch da, wo sie eigentlich gegeben wären, werden sie dadurch aufgehoben, dass die slowenen ihren anderssprachigen Mitarbeitern oder Sprechpartnern dadurch "entgegenkommen", dass sie selbst nicht slowenisch, sondern eben die Sprache des Betreffenden gebrauchen, mögen sie sie auch noch so schlecht beherrschen. Dadurch wird den Anderssprachigen nicht nur die Möglichkeit, ihr slowenisch im sprechen zu üben, genommen, sondern zugleich auch die Motivation zur spracherlernung: denn erstens kann man eine Zweisprachenunterhaltung führen, also bei seiner eigenen Sprache bleiben, und geht das nicht (da man nicht einmal imstande ist, die slowenische sprache zu verstehen), dann befleisst sich der slowenische sprechpartner freiwillig, weswegen in Gesprächen mit sprachlich gemischten Sprechpartnern schnell zur sprache des Nichtslowenen übergewechselt 
wird. Also ist nicht einmal das Verstehen des Slowenischen notwendig, um vom aktiven Sprechen ganz zu schweigen.

5.1.1 In dieser Hinsicht steht es in letzter zeit vielleicht sogar nicht mehr so schlimm, wie es noch unlängst war, wo sich Fremdsprachige auch in slowenien gegenüber der slowenischen Sprache einfach abriegeln konnten; in letzter zeit findet man ein solches Verfahren nicht mehr so ganz in ordnung und versucht, dem slowenisch Redenden doch einen Schritt entgegenzukommen, indem man zum Teil versucht, sich aus dieser "splendid isolation" zu lösen.

5.1.2. Auch die Slowenen selbst scheinen in Bezug auf ihren Sprachgebrauch sich langsam (und zu Teil) umzustellen, weswegen jetzt Anderssprachige mehr Gelegenheit haben, ihre erworbenen Kenntnisse des Slowenischen auch vorzuweisen. Dem wäre gewiss sehr förderlich, wenn sich die slowenen dieser ihrer Pflicht gegenüber den Anderssprachigen doch noch mehr bewusst wären. Es gibt aber immer noch Beispiele, wo die frühere Unterschätzung des Slowenischen von Seiten der Anderssprachigen zutage tritt, indem man seine - also nichtslowenische - sprache gebrauchen will auch in Sprechsituationen, wo man doch mit Recht erwartet, in slowenischer Sprache "bedient" zu werden, z.B. im öffentlichen Dienst, an Bank- und anderen Schaltern. Nur am Rande sei hier als unangenehme Ausnahme erwähnt, dass Studenten bei Universitätsexamen sich nicht der slowenischen Sprache zu bedienen bereit waren, sondern erwarteten, dass ihre eigene, serbokroatische gebraucht würde.

Die sprachliche "splendid isolation" selbst, wie man sie z.B. bei den Militärs in betrachtlichem Ausmass vorfindet, ist natürlich ein augenfälliger zeuge von Nichtintegriertheit (oder von Nichtintegriertseinwollen) der sich Isolierenden in die slowenische Gesellschaft, mit allen daraus folgenden Konsequenzen. Man bleibt sich dadurch fremd, oder fremder, als es nötig und nützlich ist und wäre.

5. 2 Was die Erlernung des Slowenischen anbelangt, sind besonders die nicht eben vielen studenten aus der dritten welt interessant, die in slowenien studieren; die alle lernen die 
slowenische Sprache nicht nur eben ausreichend oder sogar gut zu verstehen, sondern auch befriedigend fliessend zu sprechen. Von jenen, die bereits serbokroatisch sprechen, wenn sie nach Slowenien kommen, wird natürlich das "ererbte" Recht in Anspruch genommen, auch in Slowenien beim Serbokroatischen zu bleiben (was noch am ehesten $z u$ verstehen ist, da sich beide Sprachen doch so ähnlich sind, und zwei solche erlernte Sprachen nur schwer auseinander gehalten werden können).

5. 3 Hier stellt sich die höchst interessante Frage, wie die Slowenen selbst die Tatsache sehen; dass dem Slowenischen, ihrer Muttersprache also, in seiner Rolle als erlernungswürdiger Fremdsprache von Seiten der Immigranten so unbefriedigend wenig Beachtung geschenkt wird. In letzter zeit ist es insoweit zu einer Besserung gekommen, dass solches überhaupt wahrgenommen wird, dass man ferner, wenigstens unöffentlich, sich dazu bereit oder veranlasst findet, Stellung zu beziehen. Diese Empfindlichkeit für die (Nicht) Achtung ihrer Muttersprache als Fremdsprache lässt noch vieles zu wünschen übrig.

5.4 Ein besonderer Fall von Erlernung des Slowenischen liegt vor bei den an der Erforschung der slowenischen Sprache interessierten Sprachwissenschaftlern. Hauptsächlich sind das Slawisten, die ihre sprachkentnisse auch durch das slowenische abzurunden versuchen und es auch verwirklichen, um ihre komparativen (oder - seltener - auch kontrastiven) Studien leichter betreiben zu können. Man muss gestehen, es gibt davon nicht viele, nicht einmal unter den jugoslawischen Slawisten. Auch da wäre zu unterscheiden zwischen jenen, die Slowenisch, d.h. seine Sprachstruktur nur (gut) kennen, und jenen, die es auch sprechen, wie auch immer. Hierbei soll aber zugleich hervorgehoben werden, dass es für slawistisch wissenschaftlich Interessierte immer mehr annehmbar ist, slowenistische Probleme auch in slowenischer sprache zu behandeln.

5.5 Eine naturgegebene Benachteiligung des Slowenischen gegenüber dem Serbokroatischen wird auch darin offenbar, dass es für das Slowenische (und wohl auch für das Makedonische) ausserhalb sloweniens (bzw. Makedoniens) nicht viel Interesse an den 
Universitäten gibt.

6 Aber damit berühren wir bereits das zweite Thema unseres Vortrages, nämlich: Was wurde bisher dafür getan, dass das slowenische als Fremdsprache in bereits festgesetzten Grenzen auch wirklich erlernbar wäre.

Bei dieser Frage liesse sich vielleicht so vorgehen, dass man zuerst die Anstalten und anderen Institutionen behandelt, durch die das Slowenische als Fremdsprache gepflegt wird, und danach die Mittel und den Personalaufwand, der dazu eingesetzt wird, darlegt.

6.1 Unter den Anstalten gibt es bei uns keine Dolmetscherschule, oder wenigstens nicht an den Universitäten und Hochschulen. Die einzige solche Schule, die auch slowenisch lehrt, ist das Dolmetscherinstitut an der Universität in Graz. Slowenisch gelehrt und gelernt wird bei uns in Slowenien hauptsächlich an den sogenanten Volksuniversitäten (die keine Hochschule sind), z.B. in Ljubljana und Kranj, vahrscheinlich auch in Maribor. Solche Lehrveranstaltungen werden gewöhnlich für studenten angeboten, die zu uns kommen, um an Hochschulen zu studieren. Auch an der philosophischen Fakultät in Ljubljana gibt es einen solchen Sprachkurs (zweijährig, mit insgesamt etwa 20 studierenden), an dem hauptsächlich Studenten dieser Fakultät teilnehmen, die kein Slowenisch können. Der Kurs wird von einem Lektor durchgeführt. Ausserdem gibt es noch ein alljährliches vierzehntägiges Sommerseminar der slowenischen Sprache, hauptsächlich für slawistisch orientierte Universitätslehrer, -Hilfslehrer und -Studenten. Diese Einrichtung besteht bereits seit 17 Jahren. Ihre Bedeutung wird dadurch hervorgehoben, dass sie jedes Jahr mehr als hundert Interessierten aus der ganzen Welt (es gab schon Teilnehmer aus Japan, China und Südamerika) die Gelegenheit bietet, nicht nur ihre Sprachfähigkeit $z u$ erweitern und ihre Kentnisse von all dem, was die slowenen betrifft, sondern dass sie bei der Gelegenheit diese kleine sonderbare welt der slowenen auch in ihrer alltäglichen Unmittelbarkeit erfahren können.

6. 2 Ausserhalb sloweniens gibt es meistens Lektorate des Slowenischen, z.B. in Moskau, Krakau, Katowice, Prag, Sofija, in 
neuerer Zeit auch in Leipzig, Bukarest und (seit heuer) in Budapest im östlichen Europa, ferner drei oder vier Lektorate in österreich (Wien, Graz, Klagenfurt, Salzburg) und einige Lektorate in Westeuropa: unbeständig in München und in Regensburg, ständig (obwohl wohI mit dem Serbokroatischen verbunden) in Frankfurt, dann noch in Paris und Nottingham, in Italien aber in Triest, Udine, Rom und Neapel. In Jugoslawien selbst haben wir ausserhalb Sloweniens Lektorate an den meisten Universitäten: in Zagreb und Zadar (seit heuer auch in Osijek) in Kroatien, in Sarajevo in Bosnien, gewissermassen auch schon in Titograd in Montenegro, in Belgrad und in Novi Sad in Serbien und in Skopje in Makedonien. In Nordamerikà haben wir seit zwei Jahren ein Lektorat im Staate Kansas, für kürzere Zeit gab es sogar ein Lektorat in China. Kein Lektorat dagegen gibt es in Australien, Südameri$\mathrm{ka}$ und Kanada, keines in Afrika und Asien.

6.3 Ausser im Rahmen der Lektorate wird an einigen wenigen Stellen Slowenisch auch als Universitätsfach betreiben: das vor allem an der Universität in Moskau, in Warschau, in Klagenfurt, in Triest und Udine, vielleicht auch in Rom, teilweise auch in Prag; in Moskau allerdings in einem viel breiterem Umfang. Sonst ausserhalb Jugoslawiens wohl noch hier und da im Rahmen der Jugoslawistik, z.B. in Wien und Graz, in Jugoslawien in Novi Sad. Und das wäre ungefähr alles.

7 Am Ende soll noch über die Hilfsmittel zur Erlernung des siowenischen gesprochen werden. Wir müssen zugestehen, dass wir da nicht viel zu bieten haben. Einiges in dieser Hinsicht wurde bei uns in slowenien zusammengestellt, einiges haben andere beigesteuert.

7.1 Zur praktischen Erlernung gibt es bei uns in Slowenien seit einiger zeit (oder hat es gegeben) ein kurzgefasstes Lehrbuch für Spanisch-, Deutsch-, Französisch- und Englischsprechende (das zugrundeliegende Werk in Slowenisch von F. Jakopin verfasst, dann von besonderen Autoren den angeführten sprachen angepasst). Weit grössere ziele setzt sich zuerst für die in Nordamerika ansässigen Slowenen und ihre Nachkommen bestimmtes, aber in Wirklichkeit an Englischsprechende überhaupt gerichtetes Buch 
Zakaj ne po slovensko (Warum nicht auf slowenisch?), das in Kürze auch auf Italienisch erscheint. Im gewissen Sinne danach wurden noch zwei Lehrkurse in slowenischer sprache abgefasst: eines von einem Autorenteam, hauptsächlich wohl für Leute, die zur Erlernung des Slowenischen mehr durch Sprechdrill als durch Erkenntnis der Sprachstruktur $z$ feinerer Betrachtung und Genauigkeit geführt werden sollen, und zwar in einer slowenischsprechenden Ungebung; das zweite Buch dient ungefähr demselben Ziele, nur dass es mehr auf jene abgestimmt ist, die entweder bereits eine andere slawische sprache sprechen oder aber über einen höheren Bildungsgrad verfügen und sich daher auch sprachliche Feinheiten (z.B. den Akzent) gefallen lassen. Die Übungen in diesem Buch sind besonders reich.

Alle bisherigen Handbücher haben gemeinsam, dass sie keinerlei Vorkenntnisse des slowenischen voraussetzen und dass sie dann ihre Lernenden bis zu einer gewissen Stufe der Sprech- und Sprachbeherrschung führen, thematisch hauptsächlich im Rahmen von Gesprächen aus dem privaten Leben und aus einfachen Stadtbesichtigungserlebnissen und -begegnungen. Eine dringende Aufgabe wäre es nun, auch ein weiterführendes Handbuch zu schaffen, in welchem man bestrebt wäre, nicht nur die morphologischen Lücken auszufüllen, die nach den angeführten Sprachkursen noch offenbleiben, sondern besonders den komplizierteren syntaktischen Aufbau der slowenischen Sprache dem Lernenden zu ubermitteln und seinen Wortschatz und das Inventar der stylistischen Mittel anzureichen. Dazu bedürfte es allerdings einer wenigstens so grossen Anstrengung, wie sie 1969 in Zakaj ne po slovensko vollbracht wurde, worauf dann in kurzer zeit zwei ähnliche Arbeiten erschienen sind.

7.2 Dabei wird man sich wohl kaum auf die slowenisch-Lehrbücher für Fremde stützen können, die für Deutschsprechende bereits eine ältere, in die erste Hälfte des 19. Jahrhunderts zurückreichende Tradition aufweisen, jetzt aber geradezu verkümmert noch in Kärnten weiterleben. Dasselbe gilt teilweise auch für zwei Slowenischkurse, die nach dem zweiten Weltkrieg in Amerika erscheinen sind, einer fürs Militär bestimmt, der andere bereits nach dem Zakaj ne po slovensko. 
7.3 Am Ende dieser Übersicht seien noch etliche solcher Werke erwähnt, die vorerst den Slawen, die slowenisch lernen wollten oder sollten, zugedacht waren. Da steht am Anfang das dünne Buch von Franz Drolc für die Serbokroatischsprechenden, und ein etwas umfangreiches für die Tschechen, verfasst von Albinca Lipovec und Jan Petr. Ersteres zeichnet sich aus durch sorgfältige Auswahl verschiedener Originaltexte, die in gewisser Hinsicht die Funktionsverschiedenheit der slowenischen Texte wiedergibt. Beide Bücher sind in gewisser Hinsicht kontrastiv abgefasst, jeweils gegenüber der betreffeneden Sprache. (Auch von Janko Jurančič gibt es solch ein Buch für die Serbokroatischsprechenden.)

7. 4 Andere Ziele verfolgen endlich die Handbücher, die mehr wissenschaftlichen Charakter haben, dabei aber auch als Lehrbücher für den Einblick in den grammatikalen Aufbau des slowenischen geeignet sind. Von Arbeiten dieser Art wäre an erster Stelle mein Büchlein über die Aussprache der slowenischen Schriftsprache (auch der ganzen Satzphonetik) aus dem Jahre 1961 zu erwähnen. Auf dieses Büchlein stützt sich die Phonetik aller neueren Kurse des Slowenischen. Dann haben wir je ein Handbuch von G. O. Svane in deutscher Sprache; und von Jan Petr, das nicht so sehr praktische ziele verfolgt, sondern die ganze problematik des Slowenischen (auch die der geschichtlichen Entwicklung und der dialektalen Aufgliederung) entwirft; ein ähnliches Buch, das etwas von der russischen Sprachforschertradition geprägt ist, war auch in Moskau in Vorbereitung von Olga S. Plotnikova. 1975 erschien eine grosse Grammatik des Schriftslowenischen in französischer Sprache. Die grammatische Struktur des Slowenischen wird darin auf Grund der Tesnièrschen Strukturalmethode erfasst (allerdings mit vielen Unzulänglichkeiten, wie die Kritik zeigte). In Italien erschien 1972 eine Grammatik der slowenischen Sprache von Anton Kacin. Diese Grammatik (wie noch einige ältere, abgefasst in italienischer sprache) zeichnet sich eigentlich kaum durch Qualität aus.

8 Wir sind uns bewusst, dass das Erlernen einer Sprache wesentlich dađurch gefördert wird, dass dem Lernenden gute 
Wörterbücher in beiden Richtungen (in unserem Falle mit slowenisch als Ausgangs- und als Zielsprache) zur Verfügung stehen. Auch da stehen wir ziemlich bescheiden da. im Vergleich zu Gemeinschaften, die grosse oder grössere sprachen sprechen. Dabei sind die wörterbücher mit slowenisch als zielsprache noch verhältnismässig zufriedenstellend, soweit es sich um Englisch, Deutsch und zum Teil auch Serbokroatisch oder Italienisch handelt; schlechter bestellt ist es schon mit den französisch-, spanisch- oder slawisch (russisch-, tschechisch-, polnisch-, slowakisch-) oder ungarisch- -slowenischen wörterbüchern, gar keine Wörterbücher aber gibt es für Portugiesisch, Niederländisch, Belgisch, Dänisch, Norwegisch und Schwedisch, auch nicht für Finnisch und andere dortige sprachen und nicht für Türkisch, oder für Albanisch, Griechisch, Rumänisch. Aber viel schlimmer noch steht es mit wörterbuchern, die Slowenisch als Ausgangssprache haben. Das beste wörterbuch dieser Art ist das slowenisch-Serbokroatische von stanko Škerlj und seinen Mitarbeitern, und ein zweites von Janko Juranči (der auch ein ziemlich gutes Wörterbuch dieser beiden Sprachen in umgekehrter Richtung herausgegeben hat); irgendwie geht es noch mit dem slowenisch-Russischen Wörtebuch von Janko Kotnik unter Mitwirkung von Nikolaj F. Preobraženskij, sonst aber gibt es nur solche für einen bescheidenen schulgebrauch.

Ein Zeichen für die weniger grosse Bedeutung unserer sprache auf dem internationalen Markt ist die Tatsache, dass alle diese Wörterbücher von uns slowenen abgefasst werden mussten, und ausserhalb sloweniens gibt es sozusagen Niemanden, der die Auflagen solcher Werke abgekaufen würde. Einzige teilweise Ausnahme in dieser hinsicht ist das erwähnte wörterbuch von $\mathrm{S}$. škerlj, das Mitverfasser in Serbien hatte.

\section{Bibliographie}

I

TOPORIŠIC, J. (1978): Language of a Small Nationality in a Multilingual state. Folia Slavica, Volume 1 , Number $3, S$. 480-487; Umschlagtitel: Sociolinguistic Problems in Czechoslovakia, Hungary, Romania and Yugoslavia, Ohio, 1978. 
Edited by William R. Schmalstieg and Thomas Magner. Slavica Publishers Inc.

(1978): Mali jezik v večjezikovni skupnosti (S stališča zgodovine slovenskega (knjižnega) jezika). Slavistična revija 1977, zbornik prispevkov za VIII. mednarodni slavistið̌ni kongres $v$ Zagrebu (Ljubljani) 1978. Ljubljana, $\mathrm{s}$. 101-114.

-- Slovenisch-deutsche Sprachkontakte (1981). Kulturelle und sprachliche Minderheiten in Europa. Aspekte der europäischen Ethnolinguistik und Ethnopolitik, Akten des 4. Symposiums ubber Sprachkontakt in Europa, Mannheim 1980, Herausgegeben von P. Sture Ureland, Tübingen 1981. Max Niemeyer Verlag, S. 69-79.

PRUNC, E. (1978): Zum Problem sprachlicher Interferenzen im bilinguallen Gebiet in Kärnten. Studia Carinthiaca Slovenica

- 1. Band/1. knjiga. Klagenfuxt/Celovec 1978, 63 S.

--- (1981) : Jezikoslovno anketiranje $v$ dvojezičnih prostorih. Slavistična revija, Ljubljana, S. 435-447.

HAFNER, S. (1981): Dvojezičnost, temeljni problem slovenistike na Koroškem. Slavistična revija, Ijubljana, S."423-434.

GRUDEN, Ž. (1976/77): Prispevek k spoznavanju jezikovne situacije tržaških slovencev. Jezik in slovstvo, Ljubljana, s. 72-79.

\section{II}

SKET, J. (1904): Grundriss der slovenischen Grammatik mit Übungsbeispielen, Gesprächen und deutsch-slovenischem wörterverzeichnis. Klagenfurt, $192 \mathrm{~S}$.

TOPORIŠIČ, J. (1961): Slovenski jezik. Izgovor i intonacija s recitacijama na pločama. Acta Instituti phonetici 9, Zagreb, 1961,136 S. + 5 Spielplatten.

--- Zakaj ne po slovensko. Slovene by Direct Method. Slovenska izseljenska matica, Ljubljana, 1969, $272 \mathrm{~S} .+6$ Spielplatten.

JAKOPIN, F. (1962): Le Slovene a Votre Portée. Adapté en français par Viktor Jesenik. Slovenska izseljenska matica, Ljubljana, 1962, $115 \mathrm{~S}$. Noch in 3 Fassungen: D. Vodnik: Mö́chten sie nicht slowenisch lernen, $117 \mathrm{~s}$.; N. Vitorovic: Slovene for You, IV + 114 S.; Y. Kvas-Perona: ?Quieren hablar en esloveno?, $118 \mathrm{~S}$.

DROLC, F. (1970): Slovenski jezik. Udžbenik za škole s hrvatskosrpskim nastavnim jezikom. Zagreb, 1970, $126 \mathrm{~S}$.

STOR, M., KARLIN, P. (1970): Möchten sie slowenisch sprechen. Nachschlagebüchlein für deutsche Turisten. Staatsverlag Sloweniens, Ljubljana, $146 \mathrm{~S}$.

ANDOLJSEK, E., JEVŠENAK, L., KOROŠEC, T. (1973) : Povejmo slovensko. Državna založba Slovenije, Ljubljana, 1973, 204 S. + Kassetten. 
LIPOVEC, A., PETR, J. (1976): Učebnice slovinštiny, Praha, 264 S. GOBETZ, M., LONCAR, B. (1976, 1977) : Slovenian Language Manual/ Učbenik slovenskega jezika. Volume I/Prva knjiga, $333 \mathrm{~s}$. Volume II/Druga knjiga, $433 \mathrm{~s}$.

JUG-KRANJEC, H. (1978) : Slovenščina za tujce. Izdal Seminar slovenskega jezika, literature in kulțure, Ljubljana, 1978, 210 S. $1979^{2} ; 1980^{3}$.

\section{III.}

SVANE, G. O. (1958): Grammatik der slovenischen Schriftsprache, Copenhagen, $152 \mathrm{~S}$.

JURANČIC,, J. (1965): Slovenački jezik. Gramatika slovenačkog jezika za: Hrvate i Srbe. Državna založba Slovenije, 281 s.

BIDWELI, C. E. (1969): Outline of Slovenian Morphology. University Center for International Studies, University of Pittsburgh, Pittsburgh, $110 \mathrm{~s}$.

NEMEC, J. (1969): Grammatica della lingua slovena. Založila Tržaška tiskarna, Trst, $245 \mathrm{~S}$.

PETR, J. (1971, 1974): Zaklady slovinštiny. Universita Karlova, Praha, $140 \mathrm{~S}$.

KACIN, A. (1972): Grammatica della lingua Slovena. Državna založba Slovenije, Ijubljana, Založništvo tržaškega tiska, Trst, $371 \mathrm{~s}$.

VINCENOT, C. (1975): Essai de grammaire slovène. Mladinska knjiga, Ljubljana XXIV + $353 \mathrm{~S}$.

HEČKo, V. (1978) : Základy slovinskej gramatiky. Univerzita Komenského $\mathrm{v}$ Bratislave, $123 \mathrm{~S}$.

\section{IV}

BRADAČ, F. (1973): Slovensko-latinski slovar. Državna založba Slovenije (DZS), Ijubljana, IV + 347 S.

GRAD, A. (1979) : Slovensko-Španski slovar. DZS, $747 \mathrm{~s}$.

KOTNIK, J. (1972) : Slovensko-angleški slovar. DZS, VI + $831 \mathrm{~S}$.

- (1970): Slovensko-francoski slovar. DZS, XV + 682 S.

--- (1972): Slovensko-ruski slovar. DZS, VI + $817 \mathrm{~s}$.

- (1950) : s sodelovanjem Zvonka Bizjaka in dr. Nikolaja Preobraženskega. DZS, IV + 736 S.

ŠEBJANIČ, F. (1969): Slovensko-madžarski slovar. DZS, VIII + $185 \mathrm{~S}$.

ŠKERLJ, S. (1964, 1975), ALEKSIC, R., LATKOVIC, V.: SIovenačko-srpskohrvatski rečnik. Izdavačko preduzece Prosveta, Beograd, Državna založba Slovenije, Ljubljana, XLVI + 1303 bzW. XXXVI + $933 \mathrm{~S}$.

ŠKERLJ, R. (1976): Slovensko-Češki slovar. DZS, $461 \mathrm{~S}$. TOMŠIČ, F. (1966): Slovensko-nemški slovar. DZS, $768 \mathrm{~S}$. 
AVSEC, O. (1972): Esperantsko-slovenski in Slovensko-esperantski slovar, DZS, $303 \mathrm{~s}$.

BAJEC, A., KALAN, P. (1971): Italijansko-slovenski slovar. DZS, $843 \mathrm{~S}$.

BRADAČ, F. (1967) : Češko-slovenski slovar. DZS, VIII + $738 \mathrm{~S}$.

--- (1972): Latinsko-slovenski slovar. DZS, $609 \mathrm{~S}$.

JAKOPIN, F. (1965): Rusko-slovenski šolski slovar. Mladinska knjiga, $536 \mathrm{~S}$.

JURANCIC, J. (1972): Srbskohrvatsko-slovenski slovar. DZs, XXXVIII + $1320 \mathrm{~S}$.

GRAD, A., ŠKERIJ, R., VITOROVIČ, N. (1978): Veliki angleško-s lovenski s lovar. DZS, XV + $1377 \mathrm{~s}$.

GRAD, A. (1969): Špansko-slovenski slovar. DZS, XI + $1005 \mathrm{~S}$.

--- (1975): Francosko-slovenski slovar. DZS, XVI + $1402 \mathrm{~S}$.

PRETNAR, J. (1964): Rusko-slovenski slovar. DZS, 995 S.

SMOLEJ, V. (1976) : Slovał̌ko-slovenski slovar. DZs, $447 \mathrm{~s}$.

ŠEBJANIČ, F. (1961): Madžarsko-slovenski slovar. DZS, XXIV + 179. S.

TOMŠIČ, F. (1964): Nemško-slovenski slovar. DZS, 989 S.

VODNIK, F. (1977): Poljsko-slovenski slovar. DZS, VI, + $1247 \mathrm{~S}$.

Statistischer Anhang: Einwohner der Sozialistischen Republik slowenien

\begin{tabular}{|c|c|c|c|c|c|c|c|c|c|c|c|}
\hline Nation, Nationalit & & & 1953 & & 1961 & & & 1971 & & & 198 \\
\hline $\begin{array}{l}\text { lowenen } \\
\text { roaten }\end{array}$ & 1 & 415 & $\begin{array}{l}448 \\
978\end{array}$ & $1 \quad 522$ & 248 & 1 & $\begin{array}{r}624 \\
42\end{array}$ & $\begin{array}{l}029 \\
657\end{array}$ & 1 & $\begin{array}{r}712 \\
55\end{array}$ & \\
\hline Serben & & 11 & 225 & 13 & 609 & & 20 & 521 & & 42 & 18 \\
\hline lawen & & & - & 2 & 78 & & 6 & 7 & & 26 & 2 \\
\hline Muslimanen & & 1 & 617 & & 46 & & 3 & 231 & & 13 & 4 \\
\hline Ungarn & & 11 & 019 & 10 & 498 & & 9 & 785 & & 9 & 4 \\
\hline rangehö & & & - & & - & & 2 & 705 & & 4 & 0 \\
\hline Makedonier & & & 640 & 1 & 009 & & 1 & 613 & & 3 & 2 \\
\hline egrine & & 1 & 356 & 1 & 384 & & 1 & & & & \\
\hline Unents chiedene & & & - & & - & & 3 & 073 & & 2 & 9 \\
\hline Italiener & & & 854 & 3 & 072 & & 3 & 001 & & 2 & \\
\hline Albanier & & & 169 & & 282 & & 1 & 281 & & 1 & \\
\hline Roma & & 1 & 663 & & 158 & & & 977 & & 1 & \\
\hline Tschecher & & & 807 & & 584 & & & & & & \\
\hline Deutsche & & 1 & 617 & & & & & 422 & & & \\
\hline Polen & & & 275 & & 222 & & & 194 & & & $\begin{array}{l}20 \\
19\end{array}$ \\
\hline Russen & & & 593 & & 295 & & & 302 & & & \\
\hline
\end{tabular}




\begin{tabular}{lrrrr}
\hline Nation, Nationalität & 1953 & 1961 & 1971 & 1981 \\
\hline Ukrainer & & & 143 & 192 \\
Österreicher & 289 & 254 & 278 & 180 \\
Slowaken & 60 & 71 & 85 & 144 \\
Bulgaren & 49 & 180 & 139 & 105 \\
Rumänen & 41 & 48 & 43 & 94 \\
Türken & 68 & 135 & 53 & 87 \\
Russinen & 46 & 384 & 66 & 54 \\
Griechen & 24 & 50 & 24 & 18 \\
Wallacher & 9 & 6 & 5 & 17 \\
Juden & 15 & 21 & 72 & 9 \\
ander Nat. & 352 & 449 & 307 & 577 \\
unklar deklariert & 211 & 1154 & 2964 & 10635 \\
\hline
\end{tabular}

\section{Povzetek}

Slovenšcina kot tuji jezik: slovenski jezik govorita kot materinščino lna narodnostnem ozemlju v Jugoslaviji, na Madžarskem, v Avstriji in Italiji) niti ne cela dva milijona ljudi. Jezika, ki ga govori tako majhno število ljudi, se drugojezični večinoma ne učijo. Vendar slovenšc̆ino v sloveniji kot tuji jezik uporablja verjetno 100000 ljudi, potencialno celo čez 200000 (prim. preglednico popisa prebivalstva za 1. 1981). To so poleg raztreseno živečih Romov pripadniki italijanske in madžarske narodnostne skupnosti na svojem etničnem ozemlju, večinoma pa sicer priseljenci, in sicer pretežno iz srbohrvaško govorečega dela Jugoslavije, vendar tudi Albanci in Makedonci. K temu pridejo še srednješolci in študenti iz neslovenskega dela Jugoslavije in iz tujine (ki pa, kot še nekateri drugi, nezajeti v popis prebivalstva, nimajo stalnega prebivališc̆a v sloveniji). (Precej številni pripadniki Jugọslovanske ljudske armade, deloma tudi njihovi družinski člani; navadno tudi v sloveniji ostajajo srbohrvaško enojezični.)

Pripadniki manjšin se učijo slovenšc̆ine kot tujega jezika $v$ osnovni šoli; v srednjih šolah pa imajo slovenščino večinoma że kot učni predmet $v$ statusu materinšcine. Enako je z neslovenskimi dijaki od drugod iz Jugoslavije. Kot tuji jezik za odrasle se slovenšc̆ina poučije le malo; vec̆ina priseljencev se uči slovenšc̆ine samo $v$ neposrednem stiku s slovensko govorečimi, to pa ali pri delu ali v privatnem življenju (med drugim tudi v mešanih zakonih).

Učiti se slovenščine iz priročnikov ni ravno lahko, ker jih ni za različne stopnje obvladovanja jezika. Obstajajo pa sicer razmeroma dobri slovarji za večje evropske jezike (angleski, nemški, francoski, italijanski, ruski, španski) in za srbohrvaš-a čino, in sicer v obeh smereh. Nekaj osnovnih jezikovnih tec̆ajev slovenščine je orientiranih na posamezne tuje jezike, npr. na italijanščino ali anglešc̆ino oz. nemšcino. Razen tega je omeniti še nekaj slovnic slovenščine v nemščini, italijanšc̆ini, ena tudi V francošc̆ini. Popolnoma pa manjkajo priroc̆niki za tiste, ki bi se slovenšcine kot tujega jezika učili na višji stopnji. 
Status slovenskega jezika kot tujega bi se gotovo utrdil, ce bi se slovenci bolj zavedali svojega jezika, tj. ko bi svoj jezik uporabljali načeloma v vseh govornih položajih, s cimer bi bila dana pobuda in motivacija drugojezičnim pri nas, da bi se slovenšc̆ine bolj učili in jo potem bolj uporabljali v stiku z. nami. 